\title{
Determinants of Late Initiation for First Antenatal Care Visit Among Pregnant Women in Public Health Institutions, Dale District, Southern Ethiopia; Unmatched Case Control Study
}

\author{
Teka Senay Wolderufael ${ }^{1, *}$, Tinsay Bekele Areda ${ }^{2}$, Urgessa Warsamo Ganebo ${ }^{3}$, \\ Fasika Fanta Gebreyesus ${ }^{4}$ \\ ${ }^{1}$ Social and Population Department, Yirgalem Hospital Medical College, Yirgalem, Ethiopia \\ ${ }^{2}$ Medicine and Health Sciences College, Hawassa University Comprehensive Specialized Hospital, Hawassa, Ethiopia \\ ${ }^{3}$ School of Public Health, Hawassa University Comprehensive Specialized Hospital, Hawassa, Ethiopia \\ ${ }^{4}$ Social and Population Department, Yirgalem Hospital Medical College, Yirgalem, Ethiopia
}

Email address:

teka.senay@gmail.com (T. S. Wolderufael), tensaybekele60@gmail.com (T. B. Areda), urgessa2017@yahoo.com (U. W. Ganebo), fasikaefanta@gmail.com (F. F. Gebreyesus)

${ }^{*}$ Corresponding author

\section{To cite this article:}

Teka Senay Wolderufael, Tinsay Bekele Areda, Urgessa Warsamo Ganebo, Fasika Fanta Gebreyesus. Determinants of Late Initiation for First Antenatal Care Visit Among Pregnant Women in Public Health Institutions, Dale District, Southern Ethiopia; Unmatched Case Control Study. Science Research. Vol. 8, No. 2, 2020, pp. 31-38. doi: 10.11648/j.sr.20200802.11

Received: October 4, 2019; Accepted: April 20, 2020; Published: April 28, 2020

\begin{abstract}
Background: Late initiation to first ANC visit is the predominant problem in most developing countries including Ethiopia. Despite antenatal care services being provided for free of charge in Ethiopia, significant number of pregnancy women seek first ANC visit lately. According to EDHS 2016, about 80\% of pregnant women had first ANC visits lately. This study tried to assess predictors of late initiation for Antenatal care visit Among Pregnant Women in Public Health Institutions' Dale District, Southern Ethiopia, 2018. The study design was A facility based Unmatched Case Control Study design was employed. Data was collected from pregnant women who were attending ANC unit' by using structured questionnaire. Multistage sampling technique was employed. The Sample size for this study was calculated using EPI info software statcalc version 7.1.3. Data was edited, entered into computer and coded, descriptive, bivariate and multivariate analysis was done. The main reasons for late initiation for first ANC visits were being busy and unaware of ANC visit time. Husband's educational status and knowledge about pregnancy related danger signs were found significantly associated and had positive relationship with late start of first $\mathrm{ANC}$ visit ( $\mathrm{AOR}=4.91 ; 95 \% \mathrm{CI}: 1.516-15.914$ ) and ( $\mathrm{OOR}=2.553$; 95\% CI: 1.456-4.475) respectively. In Conclusion the main reasons for late initiation of first ANC visit during last pregnancy were being busy due to house responsibilities and unaware of ANC visit time. Husband's educational status and mothers poor knowledge about pregnancy related danger signs were found significantly predictors of late first ANC visit.
\end{abstract}

Keywords: Late Initiation, ANC Visits, Predictors, Dale District, Southern Ethiopia, Unmatched Case Control Study

\section{Background}

Women and children health issues remain an unfinished agenda and a global challenge. Efforts and investments are needed to sustain and accelerate progress if countries and the international community are to prevent maternal and child morbidity and reach the related Sustainable Development Goals (SDGs) 3.1. Globally, there has been a change in the pattern and type of obstetric outcomes, as a greater proportion of deaths and morbidities had been reduced ([1, 2]).

The timing of initiation of the first antenatal care visit is paramount for ensuring optimal care and health outcomes for women and children. Pregnancy is a crucial time to promote healthy behaviors and parenting skills. Recommended ANC visit links the woman and her family with the formal health system, increases the chance of using a skilled attendant at 
birth and contributes to good health through the life cycle [3].

The purpose of antenatal care is to monitor and improve the wellbeing of the mother and fetus. Antenatal care (ANC), which is given to pregnant women, is widely used for prevention, early diagnosis and treatment of general medical and pregnancy-related complications to ensure that each newborn child has a good start [4].

It is recommended that all pregnant women initiate antenatal care in the first trimester of pregnancy (early antenatal care visit); In developing countries, majority of pregnant women start the first ANC visit by their $2^{\text {nd }}$ or $3^{\text {rd }}$ trimester of pregnancy $([5,6,7])$.

WHO recommends that women start antenatal care at a gestational age of less than 12 weeks this is referred to as 'early antenatal care'? The 2016 ANC guidelines include a significant new recommendation that pregnant women have eight contacts with the health system during each pregnancy. Progress in the coverage of early antenatal care visits has been achieved but coverage is still far from universal. In 2013, the estimated coverage of early antenatal care visits was $24.0 \%(95 \%$ UI $21 \cdot 7-26 \cdot 5)$ in low-income countries compared with $81 \cdot 9 \%(76 \cdot 5-87 \cdot 1)$ in high-income countries [8]. Despite this progress, less than half of all women in developing regions received early antenatal care in 2013 . In contrast, the majority of women (an estimated 85\%) in developed regions had an early antenatal care contact with a health provider. In addition to inequalities between regions, the study showed significant gaps in 2013 between richer and poorer women. While the majority of women an estimated more than 4 out of 5 women in the highest income group studied accessed early antenatal care, an approximate 1 out of 4 women in the lowest income group accessed early antenatal care. Previous studies have shown that educational level, marital status, income, maternal age, occupational status, parity, intention of pregnancy, hospital type, planned pattern of care, place of delivery, previous utilization influence initiation time of antenatal care $([9,10,11,12,13])$.

In Ethiopia the situation is similar with that of the Sub Saharan African countries. EDHS 2016 results shows that low proportion of women age $15-49$; only $20 \%$ of women had their first ANC visit during the first trimester [14]. Different Studies conducted in Ethiopia so far focused on prevalence of late entry of ANC visit among pregnant women. There is lack of analytical study on predictors of late initiation to first ANC visit in study area.

\section{Methods}

This study was conducted in Sidama zone, which is located in Southern Nations, Nationalities and People's Regional State (SNNPR). Dale district is one of the 19 rural woreda's and four city Administration of Sidama zone in Southern regions of Ethiopia, which is located $45 \mathrm{KM}$ far from capital city of southern regions, Hawassa, and organized by 33 rural and 3 urban kebeles for the purpose of administration. According to 2010 E. C health report, the total Woreda's population was 241,130. The study was conducted from June-July 2018. Institution based Unmatched case control study design was employed. Source population was all mothers attending Dale district public health facilities. The study population was pregnant mothers attending Dale district health facilities for ANC services during study period pregnant mothers attending those health facilities during study period for ANC services, Pregnant woman who give verbal consent and Pregnant women who fulfills definition of cases and controls were included in the study. Pregnant women who are critically ill and unable to respond were excluded.

Multistage stages sampling technique was employed. Four health facilities were randomly selected by lottery method among 11 health centers in the woreda. Sample proportion or number of eligible pregnant mothers was calculated based on catchment population proportion and with consideration of total number of ANC visits during study period using exit interview all eligible pregnant mothers were interviewed. The Sample size for this study was calculated using Open Epi 3.5 .1 version software in consideration of $95 \%$ confidence level with $90 \%$ power for all study questions and with a ratio between cases and controls of one to two. Sample size calculation for this study was based on pregnancy intention status from study conducted in Addis Ababa that 23.9\% of women who entered late to ANC visit had unplanned pregnancy during conception with proportion of cases and controls of $23.9 \%$ and $8.2 \%$ respectively who have unplanned pregnancy during conception was considered [15]. $10 \%$ non-response rate was considered; which gives the final estimated sample size was 462 that is for cases 154 and 308 controls. So this variable gave maximum sample size possible.

A structured questionnaire was adopted from different literatures and published studies and then modified to local context. The questionnaire was prepared originally in English and then translated to Amharic. Different persons involved in retranslation back to English for checking consistencies. It was pre-tested on $5 \%$ of the sample size in one of the health institution by the trained interviewers and revised ahead of the data collection period. The edited final Amharic version was used for the actual interview. Face-to-face interview were employed. Data was collected at waiting room immediately following the consultation at ANC unit.

Data collectors were selected from each health centers who can speak local language (Sidamigna) from respective Health institutions and four public health professionals were selected to supervise the data collectors and check the questionnaire for its completeness and consistency at the end of each data collection day. Both the interviewers and supervisors were given a one days training by principal investigators on the aim of study, confidentiality and data collection techniques by going questionnaire through question by question.

Data was stored in a secured place to maintain confidentiality. Back-up of the data was made to store in different areas not to lose the data.

Variables in this study were identified based on Andersen and Newman socio-behavioral model framework of health 
services utilization. The use of models in research on utilization of health services attempts have been made to organize the different determinant factors into one explanatory concept Since timing of ANC booking is pattern of health service utilization, the selected variables was organized based on this model as follows.

The completed questionnaire from each study participant was checked for completeness and consistency by the principal investigator. Codes were given to the completed questionnaires. The principal investigator was enter the data using SPSS 16.0 statistical package Data editing and cleaning was performed to check for accuracy, consistency, \& missing values.. Data was summarized and descriptive statistics was computed for all variables according to type. Frequency, mean and standard deviation was calculated for continuous variables and categorical variables were assessed by computing frequencies. Crude odds ratio (OR) and 95\% confidence interval (CI) for each variable of interest was calculated. Finally, all variables those were found statistically significant at $\mathrm{p}<0.25$ under bivariate analysis was enter into multiple logistic regression models and adjusted odds ratio was also calculated for each exposure variables to see the effect of the independent variables on the dependent variable by controlling for confounders. $P<0.05$ was considered as statistically significant.

Quality assurance measures were undertaken during questionnaire designing, data collection and data management process. Validity of the questionnaire was maintained by using questionnaire adopted from different literatures that was used by other researchers. The instrument was pre-tested on other ANC clinics by administering it to a small group of people ( $5 \%$ of the total sample) before the actual implementation of the study and little correction on words were under taken accordingly. Data from pre-test finding was excluded from the actual data. The purpose of the study was explained for the mothers to make them frankly communicate with the data collectors. Intensive training was given for supervisors and data collectors. The principal investigator reviewed the questionnaires on daily basis for completeness and consistency and supervised the data collection sites throughout stay. Data edition was done on the same day. Cleaning and exploration of outlier responses was done after data entry and during analysis.

\section{Results}

\subsection{Socio-Demographic and Economic Characteristics of Study Respondents}

Data were collected on predisposing, enabling and need factors from the total of 459 pregnant women ( 153 cases and 306 controls), giving a response rate of $99.3 \%$. The mean maternal age of all study participants was $27 \pm 6$. For cases the mean age was $28 \pm 6$, while for controls it was $26 \pm 4$. About 48 (31.4\%) and $114(37.3 \%)$ of cases and controls respectively were aged 25-29 years, followed by $24(15.7 \%)$ and 77 (25.2\%) of cases and controls were age group of 20-24 years; the fewest mothers $1(0.7 \%)$ and $7(2.3 \%)$ of cases and controls were at age 15-19 years.

With respect to religion of the respondents majority 179 (58.5\%) and $92(60.1 \%)$ controls and cases respectively were protestants, while 101 (33.0\%) of controls and $49(32.0 \%)$ of cases were orthodox. Almost all 286 (93.5\%) and $129(84.3 \%)$ of controls and cases respectively were currently married and living with their partners.

Nearly half $160(52.3 \%)$ and more than half $103(67.3 \%)$ of control and cases respectively have not attended formal educational, while 120 (39.2\%) of controls' and 45 (29.4\%) case's partners have attended any formal education.

According to this study findings majority of controls 194 $(63.4 \%)$ and cases 96 (62.7\%) were housewives. About 183 $(59.8 \%)$ control's and $102(66.7 \%)$ of case's partners were farmers.

According to finding of this study that controls and cases who have a family size greater than five members, were 153 $(50.0 \%)$ and $85(55.6 \%)$ respectively. Information on average monthly income were collected from all participants and result showed that more than half of controls $156(51.0 \%)$ and cases $70(45.8 \%)$ have average family monthly income more than median (Table 1).

Table 1. Socio-demographic, characteristics of Study participants Southern Ethiopia June-July, 2018.

\begin{tabular}{|c|c|c|}
\hline Variable & $\begin{array}{l}\text { Controls n (\%) } \\
n=306\end{array}$ & $\begin{array}{l}\text { Cases n (\%) } \\
n=153\end{array}$ \\
\hline \multicolumn{3}{|l|}{ Maternal age in years } \\
\hline $15-19$ & $7(2.3 \%)$ & $1(0.7 \%)$ \\
\hline $20-24$ & $77(25.2 \%)$ & $24(15.7 \%)$ \\
\hline $25-29$ & $114(37.3 \%)$ & $48(31.4 \%)$ \\
\hline $30-34$ & $44(14.4 \%)$ & $44(28.8 \%)$ \\
\hline $35-39$ & $35(11.4 \%)$ & $32(20.9 \%)$ \\
\hline $40-44$ & $29(9.5 \%)$ & $4(2.6 \%)$ \\
\hline \multicolumn{3}{|l|}{ Religion } \\
\hline Protestant & $179(58.5 \%)$ & $92(60.1 \%)$ \\
\hline Orthodox & $101(33.0 \%)$ & $49(32.0 \%)$ \\
\hline Catholic & $13(4.2 \%)$ & $6(3.9 \%)$ \\
\hline Muslim & $9(2.9 \%)$ & $6(3.9 \%)$ \\
\hline Others & $4(1.3 \%)$ & $0(0.0 \%)$ \\
\hline \multicolumn{3}{|l|}{ Marital status } \\
\hline Married & $286(93.5 \%)$ & $129(84.3 \%)$ \\
\hline Divorced & $14(4.6 \%)$ & $18(11.8 \%)$ \\
\hline Single & $6(2.0 \%)$ & $6(3.9 \%)$ \\
\hline \multicolumn{3}{|l|}{ Educational status } \\
\hline No formal education & $160(52.3 \%)$ & $103(67.3 \%)$ \\
\hline Have formal education & $79(25.8 \%)$ & $30(19.6 \%)$ \\
\hline Grade 1-8 & $46(15.0 \%)$ & $12(7.8 \%)$ \\
\hline Grade $9-12$ & $16(5.2 \%)$ & $8(5.2 \%)$ \\
\hline College and above & $5(1.6 \%)$ & $0(0.0 \%)$ \\
\hline \multicolumn{3}{|l|}{ Husband education } \\
\hline No formal education & $79(25.8 \%)$ & $45(29.4 \%)$ \\
\hline Have formal education & $120(39.2 \%)$ & $45(29.4 \%)$ \\
\hline Completed grade 1-8 & $73(23.9 \%)$ & $35(22.9 \%)$ \\
\hline Completed grade 9-12 & $12(3.9 \%)$ & $18(11.8 \%)$ \\
\hline College and above & $22(7.2 \%)$ & $10(6.5 \%)$ \\
\hline \multicolumn{3}{|l|}{ Occupation } \\
\hline House wife & $194(63.4 \%)$ & $96(62.7 \%)$ \\
\hline Government employee & $20(6.5 \%)$ & $12(7.8 \%)$ \\
\hline Farmer & $17(5.6 \%)$ & $24(15.7 \%)$ \\
\hline Merchant & $75(24.5 \%)$ & $20(13.1 \%)$ \\
\hline Others & $0(0.0 \%)$ & $1(0.7 \%)$ \\
\hline
\end{tabular}




\begin{tabular}{lll}
\hline Variable & $\begin{array}{l}\text { Controls n (\%) } \\
\mathbf{n = 3 0 6}\end{array}$ & $\begin{array}{l}\text { Cases n (\%) } \\
\mathbf{n = 1 5 3}\end{array}$ \\
\hline $\begin{array}{l}\text { Husband occupation } \\
\text { Government employee }\end{array}$ & $4(1.3 \%)$ & $3(2.0 \%)$ \\
$\begin{array}{l}\text { Farmer } \\
\text { Merchant }\end{array}$ & $183(59.8 \%)$ & $102(66.7 \%)$ \\
$\begin{array}{l}\text { Others } \\
\text { Family size } \\
\leq 5\end{array}$ & $109(35.6 \%)$ & $45(29.4 \%)$ \\
$>5$ & $10(3.3 \%)$ & $3(2.0 \%)$ \\
$\begin{array}{l}\text { Average family monthly income } \\
<\text { Median }\end{array}$ & $153(50.0 \%)$ & $68(44.4 \%)$ \\
$\geq$ Median & $153(50.0 \%)$ & $85(55.6 \%)$ \\
$\begin{array}{l}\text { Average distance from home to health facility } \\
\leq \text { one hour }\end{array}$ & $150(49.0 \%)$ & $83(54.2 \%)$ \\
$<$ one hour & $174(56.9 \%)$ & $79(45.8 \%)$ \\
\hline
\end{tabular}

\subsection{Obstetric and Gynaecologic History of Study Participants}

From all the pregnant mothers who participated in the study during study period, about $323(70.4 \%)$ started ANC visit late (95\% CI: $93.1 \%-70 \%)$, but $136(29.6 \%)(95 \%$ CI: $30.5 \%-25.7 \% \%$ ) of study participants had got their first ANC visit early.

Among the total respondents, $65(42.5 \%)$ cases and 103 (33.7\%) controls were perceived the benefit of ANC visit for both mothers and baby. Regarding gravidity 71 (46.4\%) of cases and $124(40.5 \%)$ controls were Multigravida. Of total study participants $65(42.5 \%)$ cases and $122(39.9 \%)$ controls were Grand multiparous. Regarding study participants knowledge on pregnancy related danger signs, more than half of $220(71.9 \%)$ controls and $105(68.6 \%)$ cases were knowledgeable, the remaining study participants $86(28.1 \%)$ controls and $48(31.4 \%)$ cases were not knowledgeable (Table 2 and Figure 1).

Table 1. Obstetrics and Gynecology characteristics of study participants Southern Ethiopia June-July, 2018.

\begin{tabular}{lll}
\hline Variable & Controls n (\%) & Cases n (\%) \\
\hline Perception towards benefit of ANC visit & \\
For health mother & $44(14.4 \%)$ & $21(13.7 \%)$ \\
For health of fetus & $74(24.2 \%)$ & $34(22.2 \%)$ \\
For health of both & $103(33.7 \%)$ & $65(42.5 \%)$ \\
I do not know & $85(27.8 \%)$ & $33(21.6 \%)$ \\
Frequency of ANC visit & & \\
$1-3$ times & $170(55.6 \%)$ & $98(64.1 \%)$ \\
4 times & $107(35.0 \%)$ & $37(24.2 \%)$ \\
$>4$ times & $29(9.5 \%)$ & $18(11.8 \%)$ \\
knowledge on pregnancy related danger $5 i g n s$ & \\
Knowledgeable & $220(71.9 \%)$ & $105(68.6 \%)$ \\
Not knowledgeable & $86(28.1 \%)$ & $48(31.4 \%)$ \\
Was the pregnancy intended & & \\
Yes & $229(74.8 \%)$ & $121(79.1 \%)$ \\
No & $77(25.2 \%)$ & $32(20.9 \%)$ \\
Gravidity & & \\
Prim gravida & $94(30.7 \%)$ & $44(28.8 \%)$ \\
Multigravida & $88(28.8 \%)$ & $38(24.8 \%)$ \\
Grand multigravida & $124(40.5 \%)$ & $71(46.4 \%)$ \\
Parity & & \\
Prim parous & $71(23.2 \%)$ & $17(11.1 \%)$ \\
Multiparous & $113(36.9 \%)$ & $71(46.4 \%)$ \\
Grand multiparous & $122(39.9 \%)$ & $65(42.5 \%)$ \\
\hline
\end{tabular}

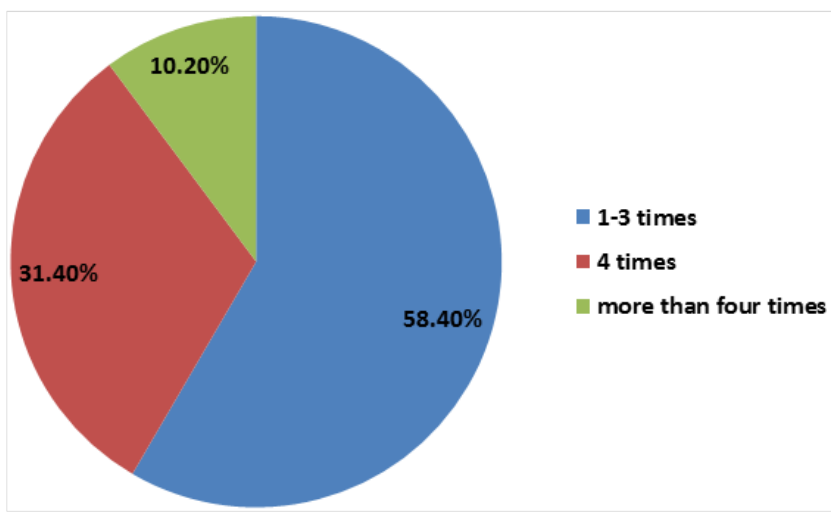

Figure 1. Frequency Distribution of ANC visits among pregnant mothers Southern Ethiopia June-July, 2018.

\subsection{Healthcare Services Related Determinants of Study Participants}

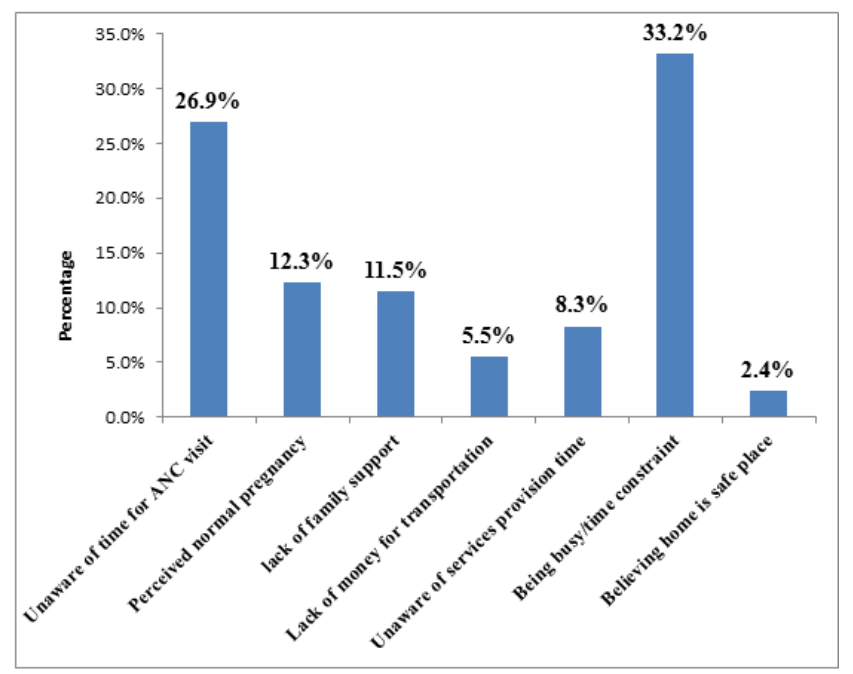

Figure 1. Reasons for late initiation of first ANC visit among pregnant mothers Dale District Sidama Zone, Southern Ethiopia from June-July 2018.

Health services related factors, average walking distance from home to health facility nearby Among pregnant mothers who took more than an hour to find health facility by walking on foot were $132(43.1 \%)$ for controls and $74(48.4 \%)$ for cases however, more than half of the study participants 174 (56.9\%) of controls and $79(51.6 \%)$ of cases were took less than an hour to get health facility. Regarding perception of pregnant mothers towards their partner's concern to support during ANC visit 191 (62.4\%) control and $86(56.2 \%)$ cases were good. But 115 (37.6\%) controls and 67 (43.8\%) cases perception were unfavorable. Perception of pregnant mothers to wards availability of ANC services, 141 (46.1\%) cases and $66(43.1 \%)$ controls were good. Less than one fourth of the study participant's perception, 78 (25.5\%) controls and 45 (29.4\%) cases perception were fair The main reasons for Late ANC visit were $33.2 \%$ mentioned as being busy due to house responsibilities; followed by $26.9 \%$ unaware of ANC visit time (Table 3 and Figure 2). 
Table 3. Health services characteristics of Study participants Southern Ethiopia June-July, 2018.

\begin{tabular}{lcc}
\hline Variable & Controls n (\%) & Cases n (\%) \\
\hline $\begin{array}{l}\text { Average distance from home to health facility } \\
\leq \text { an hour }\end{array}$ & $174(56.9 \%)$ & $79(51.6 \%)$ \\
$\geq$ an hour & $132(43.1 \%)$ & $74(48.4 \%)$ \\
$\begin{array}{l}\text { Perceived partner's concern } \\
\text { Good }\end{array}$ & $191(62.4 \%)$ & $86(56.2 \%)$ \\
Unfavourable & $115(37.6 \%)$ & $67(43.8 \%)$ \\
Perceived availability of ANC service & & \\
Good & $141(46.1 \%)$ & $66(43.1 \%)$ \\
Fair & $78(25.5 \%)$ & $45(29.4 \%)$ \\
Unfavourable & $87(28.4 \%)$ & $42(27.5 \%)$ \\
Source of information about ANC services & \\
Health Extension Workers & $44(14.4 \%)$ & $40(26.1 \%)$ \\
Health professionals & $104(34.0 \%)$ & $45(29.4 \%)$ \\
Community Health Agent & $52(17.0 \%)$ & $23(15.0 \%)$ \\
friends or relatives & $30(9.8 \%)$ & $10(6.5 \%)$ \\
Others & $76(24.8 \%)$ & $35(22.9 \%)$ \\
\hline
\end{tabular}

\section{Discussions}

5 December 2017 | WHO recommends that women start antenatal care at a gestational age of less than 12 weeks this is referred to as 'early antenatal care'. Early antenatal care is a critical opportunity for health providers to deliver care and support, and to give information, to pregnant women in the first trimester of pregnancy [16]. In this study about $29.6 \%$ of respondents had started their early ANC visit within the recommended time but, $70.4 \% \%$ of pregnant women initiated antenatal care at after four months of their gestation period. Timely initiation of ANC service utilization is important for early detection and treatment of adverse pregnancy related outcomes. This finding indicates that significant number of study participants starts ANC visits lately. However, as studies shown in developed countries women reported late or no prenatal care lowest Proportions (4\%) in USA and highest percentage in Namibia $([17,18])$.

It is higher than when compare to other studies done in Gamo Gofa Zone, South Ethiopia (17.4\%), Addis Ababa, Ethiopia (23.9\%), but it was similar compare to study done in Debre Markos town, North West Ethiopia (33.4\%) ([21, 15, 19]).

The mean gestational age at the time of first ANC visit was $19.03 \pm 5.21$ weeks. This finding was similar with study done in Myanmar (18 weeks) [13].

The main reasons for Late ANC visit were 33.2\% mentioned as being busy due to house responsibilities; followed by $26.9 \%$ unaware of ANC visit time. This finding was consistent with study done in Ethiopia [21]. From total respondents about $31.4 \%$ of pregnant mothers were attended at least four times ANC visit during their current pregnancy, this also consistent with EDHS, 2016 which was thirty-two percent of women had at least four ANC visits during their last pregnancy. About $31.6 \%$ of mothers were start their first ANC visit in the first trimester; this result was much lower compared to study in North West Ethiopia (51.9\%), and higher when compared to other study done in Ethiopia (10\%) $([14,21])$. This difference might be due to time and scope of the study.
Pregnant mother's husband education status was positively associated with late ANC initiation the result shown that, pregnant women's husbands educational level 9-12 grade completed were found to be more likely to have early initiation of ANC when compared with others ( $\mathrm{AOR}=4.91$; 95\% CI: 1.516-15.914) ( $\mathrm{P}$ Value $=008$ ). This is might be husbands education status gives a chance to get information about ANC visit time and services delivery for decision making and allow or tell their wives to visit health facilities early. This study finding was consistent with the findings of studies conducted in Southern Ethiopia, North West Ethiopia and Nigeria ([20, 21, 22, 23]).

Even if, the maternal and child health services given for free the study participants Average family monthly income was one of the predictor's of late first ANC visit. The final multivariate logistic regression analysis shown those pregnant mothers with average monthly income $<$ Median Eth Birr were three times more likely to seek first ANC visit late when compared to $\geq$ median Eth birr $(\mathrm{AOR}=2.969 ; 95 \%$ CI: 1.031-8.549). This study was similar with studies done in Addis Ababa, Ethiopia, North West Ethiopia and Kenya ([15, $21,24,25])$.

Regarding age at first pregnancy, pregnant women at age range of $<24$ years were 4.4 times more likely to start ANC visit lately than women whose age above 25-29 years ( $\mathrm{AOR}=4.370 ; 95 \% \mathrm{CI}: 1.432-13.333)$. Maternal age has been proven to be both negatively and positively affects the initiation time to Antenatal Care visit. In Surveys conducted in Nigeria demonstrates that teenage mothers and younger women are less probable when compared to pregnant mothers in age range between 25-29 years more than adult female who were less than 25 years [22]. The maternal death rate is three times higher for teenage mothers than for women in the 20-29 age groups. Teenage pregnancy also tends to close off opportunities for education and training. The younger a woman is when she first gives birth, the longer her total child-bearing period and the more children she is likely to have. This, too, increases the risks to the life and health of both mothers and children. The finding of this study was similar with various studies have found mixed evidence of an association between age at first pregnancy and late initiation to first ANC visit. Studies done in Nigeria, Namibia and Ethiopia Shown that young age women has been identified as a predisposing determinant for late initiation of ANC visits $([17,19,22])$.

Perception about danger signs of pregnancy was found to be an independent predictor of late initiation of first ANC visit. Pregnant Women who had no perception of the danger signs of pregnancy were 2.5 times more likely to seek ANC visit lately in their last pregnancy $(\mathrm{AOR}=2.553 ; 95 \% \mathrm{CI}$ : 1.456-4.475). This might be due to an inadequate understanding of health threats during pregnancy and this finding was similar with other studies done in, where increasing awareness of women regarding the potential health problems that they may encounter during their pregnancy improve their service seeking timing an inadequate understanding of health threats during pregnancy. 
This result was consistent with studies done Ethiopia, Namibia, Nigeria and Colombia ([19, 20, 21, 26]). (Table 4).

Table 2. Multivariate Determinants of Late initiation to first ANC visits among Study participants Southern Ethiopia June-July, 2018.

\begin{tabular}{|c|c|c|c|c|}
\hline \multirow{2}{*}{ Variable } & \multirow{2}{*}{$\begin{array}{l}\text { Controls n (\%) } \\
\mathrm{n}=306 \\
\end{array}$} & \multirow{2}{*}{$\begin{array}{l}\text { Cases n (\%) } \\
n=153 \\
\end{array}$} & \multirow{2}{*}{ Crude OR (95\% CI) } & \multirow{2}{*}{ AOR $(95 \% C I)$} \\
\hline & & & & \\
\hline \multicolumn{5}{|c|}{ Husband educational status } \\
\hline No formal education & $79(25.8 \%)$ & $45(29.4 \%)$ & $1.253(.545-2.881)$ & $.914(.342-2.445)$ \\
\hline Have formal education & $120(39.2 \%)$ & $45(29.4 \%)$ & $.825(.363-1.877)$ & $.787(.300-2.065)$ \\
\hline Completed grade 1-8 & $73(23.9 \%)$ & $35(22.9 \%)$ & $1.055(.451-2.466)$ & $1.268(.467-3.443)$ \\
\hline Completed grade 9-12 & $12(3.9 \%)$ & $18(11.8 \%)$ & $3.300(1.160-9.384)$ & $4.91(1.516-15.914)^{* *}$ \\
\hline College and above & $22(7.2 \%)$ & $10(6.5 \%)$ & 1 & 1 \\
\hline \multicolumn{5}{|c|}{ Family average monthly income } \\
\hline$<$ Median & $150(49.0 \%)$ & $83(54.2 \%)$ & $1.23(.836-1.820)$ & $2.969(1.031-8.549)^{* *}$ \\
\hline$\geq$ Median & $156(51.0 \%)$ & $70(45.8 \%)$ & 1 & 1 \\
\hline \multicolumn{5}{|l|}{ Age at first pregnancy } \\
\hline $15-19$ & $107(35.0 \%)$ & $50(32.7 \%)$ & $.988(.647-1.509)$ & $.729(.391-1.360)$ \\
\hline $20-24$ & $182(59.5 \%)$ & $84(54.9 \%)$ & $2.392(1.146-4.990)$ & $4.370(1.432-13.333)^{* *}$ \\
\hline $25-29$ & $17(5.6 \%)$ & $19(12.4 \%)$ & 1 & 1 \\
\hline \multicolumn{5}{|l|}{ Gravidity } \\
\hline Prim gravida & $94(30.7 \%)$ & $44(28.8 \%)$ & $.818(.515-1.297)$ & $.740(.396-1.384)$ \\
\hline Multigravida & $88(28.8 \%)$ & $38(24.8 \%)$ & $.754(.467-1.218)$ & $.441(.230-.845)$ \\
\hline Grand multigravida & $124(40.5 \%)$ & $71(46.4 \%)$ & 1 & 1 \\
\hline \multicolumn{5}{|l|}{ Parity } \\
\hline Prim parous & $71(23.2 \%)$ & $17(11.1 \%)$ & $.449(.244-.826)$ & $.053(.005-.616)$ \\
\hline Multiparous & $113(36.9 \%)$ & $71(46.4 \%)$ & $1.179(.773-1.800)$ & $2.009(.757-5.330)$ \\
\hline Grand multiparous & $122(39.9 \%)$ & $65(42.5 \%)$ & 1 & 1 \\
\hline \multicolumn{5}{|c|}{ knowledge on the timing of ANC visit } \\
\hline Knowledgeable & $220(71.9 \%)$ & $105(68.6 \%)$ & 1 & 1 \\
\hline Not knowledgeable & $86(28.1 \%)$ & $48(31.4 \%)$ & $.855(.560-1.305)$ & $2.553(1.456-4.475)^{* *}$ \\
\hline
\end{tabular}

\section{Limitations of the Study}

Recall bias may be introduced during data collection time as some of the variables need a recall to situations happened few weeks/months back to the actual data collection time. Selection bias is also common problem like other case control studies. The data collectors were from the ANC unit of the health facilities. This might have introduced some degree of information bias in the study. The study population includes only pregnant women who started first ANC visit later than early to first trimester and during the current pregnancy which might limit other pregnant women initiated first ANC visit late during the previous pregnancies. As the study subjects came to health institutions self- selected and have access (Geographic, Financial and other) the study may not represent the general public.

\section{Conclusions}

Late initiation for first ANC visit in Ethiopia is high as compared to other sub-Saharan Africa Countries. According to this study the Predictor's of late first ANC visit were Husband's educational status, family income, age at first pregnancy, knowledge about pregnancy related danger signs were Among variable found significantly associated and had positive relationship with late start of first ANC visit. The district and zonal health offices should work on creating awareness about the problems of late initiation of first ANC visits for mothers and their husband's. On the other hand, awareness issues about the benefit of timely ANC Visit should be given to their husband's. It is also better: to strengthening health extension program with due attention to $\mathrm{MCH}$, health education promotion and communication packages (designed with local language (Sidamigna) using local FM radios. Health professionals working in the health facility should counsel pregnant women to come ANC visits as early as the fourth month and before instead of waiting until pregnant women experience health problems.

\section{List of Abbreviations}

ANC: Antenatal Care

AOR: Adjusted Odds Ratio

C.I: Confidence Interval

DHS: Demographic and Health Survey

EDHS: Ethiopian Demographic and Health Survey

EJHD: Ethiopian Journal of Health Development

MPH: Master in Public Health

OR: Odds Ratio

SDGs: Sustainable Development Goals

SNNPRS: South Nations Nationalities' Peoples Regional State

SPSS: Statistical Package for Social Science

RHB: Regional health bureau

SSA: Sub-Saharan African countries

WHO: World health organization

YHMC: Yirgalem Hospital Medical College 


\section{Availability of Data and Materials}

The datasets generated using SPSS version 20.0 and/or analyzed during the current study are not publicly available due unable to generate in web link to datasets, but are available from the corresponding author. Data will be provided in a supplementary file.

\section{Competing Interests}

There is no competing interest with the presented data as external data collectors collected it. There was not financial interest between the funder and the research institution and us. We, the researchers, have no any form of competing financial and non-financial interest between us.

\section{Funding}

We would like to thank Yirgalem Hospital Medical College for financial support. The Funding Institution did not have a role in the design; data collection, analysis, and interpretation of data or; in writing the manuscript.

\section{Authors' Contributions}

TW, TA, UG and FG all authors have made significant contribution in the idea Conception and proposal development, TA, FG and UG participated data collection tool development, supervision during data collection process and final Report writing, TW participated in data analysis, and manuscript preparation process of this study work. All authors have participated in manuscript review. All authors read and approved the final manuscript.

\section{Acknowledgements}

We are grateful to Thank Dale District Health Offices and Sidama Zone Health Department for their collaboration and permission to conduct the study. We also acknowledge our study participants for providing the necessary information and the data collectors for collecting the data with due care.

\section{Ethical Approval}

Before starting the data collection, process, and ethical approval was obtained from Yirgalem Hospital Medical College. Official letter of cooperation was also obtained from respective district health offices. Data collection then was conducted after explaining the aim of the study and its possible benefits to the study participant and the heath institution at large. Verbal consent was obtained after explaining their right not to answer any of the questions or terminate the interview and would not give laboratory specimens, if they will not be comfortable. In order to keep confidentiality of Information; in addition, there was not being disclosure for any name of the study participant in relation to the finding.

\section{Consent for Publication}

Consent for publication refers to consent for the publication of identifying images or other personal or clinical details of participants that compromise anonymity. Seeing, as this is not applicable to your manuscript please state "Not Applicable" in this section.

\section{References}

[1] Byass $P$ et al. Diversity and divergence the dynamic burden of poor maternal health. Lancet 2016,. 388 (2164-75).

[2] WHO. Strategies toward ending preventable maternal mortality. Geneva: World Health Organization, 2017.

[3] Ornella Lincetto SM-A, Patricia Gomez, Stephen Munjanja,. Opportunities for Africa's Newborns. Focused antenatal care (ANC): The four-visit ANC model outlined in WHO clinical guidelines 2015 .

[4] Magoma M, Requejo J, Campbell OM, Cousens S, Filippi V. High ANC coverage and low skilled attendance in a rural Tanzanian district: a case for implementing a birth plan intervention. BMC pregnancy and childbirth. 2010; 10: 13. Epub 2010/03/23.

[5] Miller J, Hazari P. What's the significance of the ANC? Nursing. 2012; 42 (2): 68. Epub 2012/01/19.

[6] Mohammed F, Musa A, Amano A. Prevalence and determinants of unintended pregnancy among pregnant woman attending ANC at Gelemso General Hospital, Oromiya Region, East Ethiopia: a facility based crosssectional study. BMC women's health. 2016; 16 (1): 56. Epub 2016/08/19.

[7] Oladokun A et al. Proximate predictors of early antenatal registration among Nigerian pregnant women. Ann Afr Med. 2010; 9 (4): 222-5.

[8] Ann-Beth Moller MP, Doris Chou, Lale Say,. Early antenatal care visit: a systematic analysis of regional and global levels and trends of coverage from 1990 to 2013. Lancet Glob Health 2017,. 2017; 5: e977-83.

[9] Beeckman K, Louckx F, Putman K. Determinants of the number of antenatal visits in a metropolitan region. BMC public health. 2010; 10: 527. Epub 2010/09/03.

[10] USAID U, S persident's malaria intatives. $2016 \mathrm{WHO}$ Antenatal Care Guidelines. March 2018.

[11] Graham W, Woodd S, Byass P, Filippi V, Gon G, Virgo S, et al. Diversity and divergence: the dynamic burden of poor maternal health. Lancet. 2016; 388 (10056): 2164-75. Epub 2016/09/20.

[12] Moller AB, Petzold M, Chou D, Say L. Early antenatal care visit: a systematic analysis of regional and global levels and trends of coverage from 1990 to 2013. The Lancet Global health. 2017; 5 (10): e977-e83. Epub 2017/09/16.

[13] Aung TZ OW, Khaing W, Lwin N, Dar HT, Late initiation of antenatal care and its determinants: a hospital based crosssectional study. Int J Community Med Public Health 2016; 2016; 3:: 900-5. 
[14] Central Statistical Agency,. Demographic and Health Survey Addis Ababa, Ethiopia July 2017.

[15] Gebrekidan K, Worku A. Factors associated with late ANC initiation among pregnant women in select public health centers of Addis Ababa, Ethiopia: unmatched case-control study design. Pragmatic and observational research. 2017; 8: 223-30. Epub 2017/11/16.

[16] WHO. Sexual and reproductive health. 2017.

[17] Thogarapalli N, Mkandawire P, Kangmennaang J, Luginaah I, Arku G. Gestational age at first antenatal visit in Namibia. International journal of public health. 2016; 61 (9): 1089-97. Epub 2016/09/03.

[18] Michelle J. K. et al. National VitalStatistics Reports Timing and Adequacy of Prenatal Care in the United States, 2016

[19] Gebremeskel F, Dibaba Y, Admassu B. Timing of first antenatal care attendance and associated factors among pregnant women in Arba Minch Town and Arba Minch District, Gamo Gofa Zone, south Ethiopia. Journal of environmental and public health. 2015; 2015: 971506. Epub 2015/11/07.

[20] Mengesha Boko Geta WWY. Early Initiation of Antenatal Care and Factors Associated with Early Antenatal Care Initiation at Health Facilities in Southern Ethiopia. HINDAWI. 2017; 6 (Advances in Public Health).
[21] Ewunetie et al. DELAY on first antenatal care visit and its associated factors among pregnant women in public health facilities of Debre Markos town, North West Ethiopia. BMC Pregnancy and Childbirth (2018) 2018; 18: 173.

[22] Aliyu AA, Dahiru T. Predictors of delayed Antenatal Care (ANC) visits in Nigeria: secondary analysis of 2013 Nigeria Demographic and Health Survey (NDHS). The Pan African medical journal. 2017; 26: 124. Epub 2017/05/24.

[23] Wolde F, Mulaw Z, Zena T, Biadgo B, Limenih MA. Determinants of late initiation for antenatal care follow up: the case of northern Ethiopian pregnant women. BMC research notes. 2018; 11 (1): 837. Epub 2018/11/30.

[24] Nyongesa C, Xu X, Hall JJ, Macharia WM, Yego F, Hall B. Factors influencing choice of skilled birth attendance at ANC: evidence from the Kenya demographic health survey. BMC pregnancy and childbirth. 2018; 18 (1): 88. Epub 2018/04/11.

[25] Weldemariam S, Damte A, Endris K, Palcon MC, Tesfay K, Berhe A, et al. Late antenatal care initiation: the case of public health centers in Ethiopia. BMC research notes. 2018; 11 (1): 562. Epub 2018/08/08.

[26] Cáceres-Manrique FdM, Ruiz-Rodríguez M. Prevalence of late initiation of prenatal care. Association with the socioeconomic level of the pregnant woman. Cross-sectional study. Bucaramanga, Colombia, 2014-2015. Revista Colombiana de Obstetricia y Ginecología. 2018; 69: 22-31. 